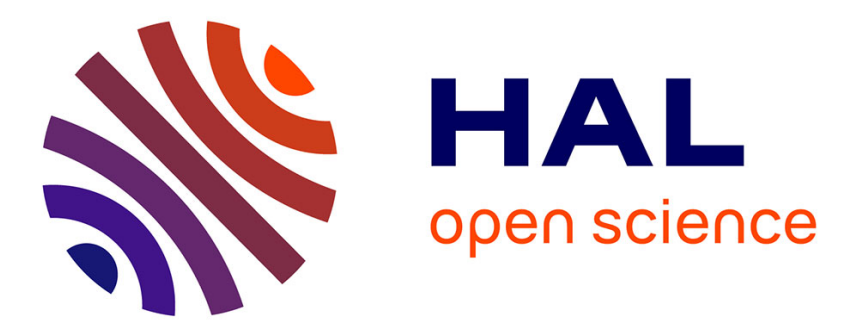

\title{
Batch copper ion binding and exchange properties of peat
}

Xiao-Hua Chen, Gosset Thierry, Daniel R. Thevenot

\section{To cite this version:}

Xiao-Hua Chen, Gosset Thierry, Daniel R. Thevenot. Batch copper ion binding and exchange properties of peat. Water Research, 1990, 24 (12), pp.1463-1491. hal-01084540

\section{HAL Id: hal-01084540 \\ https://hal-enpc.archives-ouvertes.fr/hal-01084540}

Submitted on 19 Nov 2014

HAL is a multi-disciplinary open access archive for the deposit and dissemination of scientific research documents, whether they are published or not. The documents may come from teaching and research institutions in France or abroad, or from public or private research centers.
L'archive ouverte pluridisciplinaire HAL, est destinée au dépôt et à la diffusion de documents scientifiques de niveau recherche, publiés ou non, émanant des établissements d'enseignement et de recherche français ou étrangers, des laboratoires publics ou privés.

\section{(c)(1)}

Distributed under a Creative Commons Attribution| 4.0 International License 


\title{
BATCH COPPER ION BINDING AND EXCHANGE PROPERTIES OF PEAT
}

\author{
XIAO-HuA Chen ${ }^{1}$, Thierry Gosset ${ }^{2}$, and Daniel R. Thévenot ${ }^{3, *}$ (10 \\ ${ }^{1}$ Centre de Recherche Interdépartemental pour le Traitement des Eaux Résiduaires (CRITER), 82, avenue \\ Kléber, 92700 Colombes, ${ }^{2}$ Bureau Veritas, Direction Régionale Ile de France Construction et Sécurité, \\ 21/23 grande Allée du 12 février 1934, 77186 Noisiel and ${ }^{3}$ Laboratoire de Bioélectrochimie et d'Analyse \\ du Milieu (LABAM), U.F.R. de Sciences et de Technologie, Université Paris-Val de Marne, Avenue du \\ Général de Gaulle, 94100 Créteil Cedex, France
}

(First received June 1988; accepted in revised form April 1990)

\begin{abstract}
Cupric ion fixation by raw peat is likely involved in both cation exchange with $\mathrm{H}^{+}, \mathrm{Ca}^{2+}, \mathrm{Mg}^{2+}$ and adsorption-complexation, i.e. fixation of the same equivalent of copper ions and anions $\left(\mathrm{NO}_{3}^{-}\right)$ without any ion release. The importance of both reactions depends largely on initial copper concentration, peat type and $\mathrm{pH}$. Isotherms of copper (initial concentration ranging between 1 and $20 \mathrm{mM}$ ) fixation on two types of peat (eutrophic and oligotrophic peat at $30 \mathrm{~g} \mathrm{d.w./1} \mathrm{at} \mathrm{pH} \mathrm{ranging} \mathrm{between} 2$ and 4) showed that the higher the initial cupric concentration, the more important is this complexation reaction; over this initial cupric concentration range, ion exchange sites were relatively saturated and reached 308 and $101 \mathrm{mmol} / \mathrm{kg} \mathrm{d}$.w. for eutrophic and oligotrophic peat whereas no saturation was found for complexation sites, their capacity attaining up to 74 and $119 \mathrm{mmol} / \mathrm{kg} \mathrm{d.w.,} \mathrm{respectively.}$

The apparent equilibrium constant for ion exchange with acid-treated peat (initial $\mathrm{pH} 4.0,30 \mathrm{~g}$ d.w./1) for various metal binding on both peat sites ranged between 1.1 and 10.8 in $15 \mathrm{mM}$ metallic solutions. The apparent affinity in batch conditions for 5 elements may be compared according to the apparent global equilibrium constants, ranging between $1.1 \times 10^{-6}$ and $20.2 \times 10^{-6}: \mathrm{Pb}>\mathrm{Cu}>\mathrm{Ca}>\mathrm{Mg}, \mathrm{Zn}$ for eutrophic peat and $\mathrm{Pb}>\mathrm{Ca}>\mathrm{Cu}>\mathrm{Mg}, \mathrm{Zn}$ for oligotrophic peat.
\end{abstract}

Key words - peat, metal cation, ion exchange, adsorption, complexation equilibrium, electroneutrality

\section{INTRODUCTION}

Peat has long been recognized as a natural humic substance trapping cations (Bunzl, 1974; Bunzl et al., 1976). Its carboxylic, phenolic and hydroxylic functional groups play ion exchange and complexation roles during the fixation of metal ions from solution (Smith et al., 1977; Bloom and McBride, 1979). Batch experiments and assays using columns have been extensively exploited by Aho and Tummavuori (1984) and Ansted and MacCarthy (1984) so as its application for the treatment of metal-containing effluents in industry (Coupal and Lalancette, 1976). As far as the mechanism of reaction between ionic metal and peat is concerned, results seem very different according to the peat used. Some authors like Aho and Tummavuori (1984) and Bunzl et al. (1976) have found that only ion exchange exists, one divalent metal ion being exchanged with two hydrogen ions. Other authors have reported that the mechanism is both ion exchange and complexation (Coleman et al., 1956). With the same peat samples used in this work, i.e. eutrophic "Heurteauville" and oligotrophic "Floratorf" types, Gosset (1986) has concluded that complexation mainly occurs during metal fixation by peat but he found later (Gosset et al., 1986), during

*Author to whom all correspondence should be addressed. experiments of metal desorption by $\mathrm{HCl}(\mathrm{pH} 1.5)$ in columns, that ion exchange between $\mathrm{H}^{+}$and metal cations occurred and that about $90 \%$ of metal cations were displaced from these peat exchangers. The same desorption results were also reported by Bunzl et al. (1976) and Dissanayake and Weerasooriya (1981). But a measure of hydrogen ions release is not sufficient to study the phenomenon of ion exchange especially when raw peats are used, since other metal cations may have been adsorbed previously in its natural environment. The purpose of the work is to evaluate the ion exchange and complexation properties of peats in batch with a complete balance of anion and cation exchanges during cupric ion fixation.

\section{MATERIALS AND METHODS}

\section{Peat samples and chemical reagents}

Two types of peat were used, an eutrophic peat called "Heurteauville", which contained $80 \%$ water, and an oligotrophic one called "Floratorf", with $50 \%$ water, both being commercially available in France for agriculture purpose.

Eutrophic peat was formed in alluvial plains supplied by well mineralized water. This kind of peat is poor in cellulose but rich in humic substances. Oligotrophic peat is a sphagnum one which is more acid than eutrophic peat and contains more organic matter than the first. Both peats containing about $75-85 \%$ humic acid and $15-25 \%$ fulvic acid. 
Two methods of peat pre-treatment were used for this study compared to raw peat with no pre-treatment:

(a) acid treatment, i.e. raw peat samples were shaken vigorously in $100 \mathrm{ml}$ of $1 \mathrm{~N} \mathrm{HCl}$ in polyethylene bottles for several hours until no cation release was observed and repeated washings with distilled water were followed till the $\mathrm{pH}$ of peat suspensions reached 4.0 ; at each step peat samples and supernatants were separated by centrifugation;

(b) thermal treatment, i.e. $24 \mathrm{~h}$ drying at $100^{\circ} \mathrm{C}$.

Metallic salts used in this work were cupric and lead nitrate and zinc, calcium and nagnesium chlorides. All metallic salts and chemical were of analytical grade (Prolabo P.A., Paris, France).

\section{Solution analysis}

Concentration of metallic cations was determined by acetylene-air flame atomic absorption spectrophotometry (Perkin-Elmer 2380) with single element hollow cathode lamps.

Concentration of nitrates was determined by potentiometry using a nitrate specific electrode $\left(\mathrm{pNO}_{3}\right)$ and a $\mathrm{Ag} / \mathrm{AgCl}$ reference electrode connected to an ionometer (SOLEATACUSSEL IONOMATE 80, Villeurbanne, France) and a programmable HP 70S calculator. A colorimeter (SKALAR Model 5100) linked with an automatic sampler (Sampler 1000) and a calculator (Data system 8500/01) was also used for nitrate analysis during the determination of fixation isotherms and of $\mathrm{pH}$ dependence of these equilibria. Concentration of $\mathrm{Cl}^{-}$, if necessary, was determined by $\mathrm{AgNO}_{3}$ titration method.

\section{Proton exchangeable metallic cations in raw peat}

Two samples of $3 \mathrm{~g}$ dry weight (d.w.) raw peat (eutrophic or oligotrophic) were mixed into $100 \mathrm{ml}$ of $2 \mathrm{M} \mathrm{HCl}$. Peat suspensions were shaken for $24 \mathrm{~h}$ at room temperature. Supernatants were separated by centrifugation at $6000-8000 \mathrm{rpm}$ during 5-10 min. Amounts of metal cations were determined in supernatants and expressed in $\mathrm{mg} / \mathrm{kg}$ d.w. or mequiv $/ \mathrm{kg}$ d.w.

\section{Procedure for metal fixation by peat}

Peat samples were swollen and homogenized with $100 \mathrm{ml}$ of distilled water during $2448 \mathrm{~h}$ followed by centrifugation or vacuum filtration to withdraw supernatants. The same concentration of peat, i.e. $30 \mathrm{~g} \mathrm{~d}$.w. $/ 1$ (3 g dry weight peat in $100 \mathrm{ml}$ cupric solution or $1.5 \mathrm{~g}$ dry weight in $50 \mathrm{ml}$ solution) was used for all experiments. In order to observe more correctly ion exchange between metal ions and $\mathrm{H}^{+}$, the $\mathrm{pH}$ of cupric solutions was adjusted to the same level as peat suspension by addition of $0.1 \mathrm{~N} \mathrm{NaOH}$ or $\mathrm{HCl}$ solutions except for the experiment of $\mathrm{pH}$ influence on copper fixation. Ninety min of contact time were chosen since we have found previously that in such conditions, equilibrium was reached within a couple of minutes (Chen, 1986; Kadlec and Keoleian, 1986).

(a) Copper fixation reactions by peat. Three grams of raw peat (on the basis of dry weight) were introduced into $100 \mathrm{ml}$ of $10 \mathrm{mM}$ cupric solution. Peat suspensions were stirred during $90 \mathrm{~min}$ and centrifuged at $4800-8500 \mathrm{~g}$ for $10 \mathrm{~min}$.
The initial and final concentrations of $\mathrm{Cu}^{2+}, \mathrm{Ca}^{2+}, \mathrm{Mg}^{2+}$, $\mathrm{H}^{+}$and $\mathrm{NO}_{3}^{-}$were measured except for the initial concentration of $\mathrm{NO}_{3}^{-}$which was calculated form initial cupric nitrate concentration: over the $\mathrm{pH}$ and concentration range investigated, we observed that copper nitrate in the initial solution contains only $\mathrm{Cu}^{2+}$ and $\mathrm{NO}_{3}^{-}$ions. The amount of fixed and released ions were determined on supernatants.

(b) Influence of initial cupric concentration upon its fixations. Eight samples of heat-treated dry eutrophic peat $(30 \mathrm{~g} / \mathrm{l})$ previously swollen with distilled water were mixed with 8 samples of $50 \mathrm{ml}$ cupric solution (initial $\mathrm{pH} \mathrm{5.0),}$ initial concentration of which ranged between 0 and $20 \mathrm{mM}$. Temperature was fixed at about $20^{\circ} \mathrm{C}$. After $90 \mathrm{~min}$ contact time of peat and metal solution, the liquid and solid phases were separated by vacuum filtration and the supernatants were collected. Concentrations of $\mathrm{H}^{+}, \mathrm{Ca}^{2+}, \mathrm{Cu}^{2+}, \mathrm{Mg}^{2+}$ and $\mathrm{NO}_{3}^{-}$at equilibrium were measured on supernatants.

Eight samples were used for the heat-treated oligotrophic peat $(30 \mathrm{~g} / \mathrm{l})$ experiment. The same experimental conditions were employed except for the initial $\mathrm{pH}$ which was adjusted to 3.5 because this is its natural value when oligotrophic peat is swollen in distilled water. The concentration of $\mathrm{NO}_{3}^{-}$was determined by colorimetry and concentrations of $\mathrm{H}^{+}, \mathrm{Ca}^{2+}$ and $\mathrm{Mg}^{2+}$ measured by atomic absorption spectrophotometry as described above.

(c) Influence of initial pH on copper fixation. Five samples of heat-treated peat $(1.5 \mathrm{~g}$, eutrophic $\mathrm{pH} 5.0$ or oligotrophic $\mathrm{pH} 3.5$ ) pre-homogenized in distilled water were mixed into 5 samples of $50 \mathrm{ml}(10 \mathrm{mM})$ cupric solution, the $\mathrm{pH}$ of which was adjusted to $1.7,3,4,5$ and 6 , respectively. After $90 \mathrm{~min}$ equilibration, supernatants were vacuum filtrated and collected for cations and anion analysis.

(d) Apparent equilibrium constant determination. Five samples of acid-treated peat ( $3 \mathrm{~g}$ dry weight), whose $\mathrm{pH}$ reached 4.0 when swollen in distilled water for several hours, were mixed with 5 selected metal solutions, each containing one of the following cations: $\mathrm{Pb}^{2+}, \mathrm{Cu}^{2+}, \mathrm{Mg}^{2+}, \mathrm{Ca}^{2+}$ and $\mathrm{Zn}^{2+}(15 \mathrm{mM}$, initial $\mathrm{pH} 4.0)$ at room temperature. Supernatants were analysed for cations and anions.

To evaluate the total amount of sites of fixation, we added peat samples, previously equilibrated with $15 \mathrm{mM}$ metallic solution and separated from supernatant, into $100 \mathrm{ml}$ of $600 \mathrm{mM}$ of each selected metal solution over initial $\mathrm{pH}$ range 3.1-3.5: cupric concentration was measured in supernatant solution after 90 min contact time.

\section{RESULTS AND DISCUSSION}

\section{Proton exchangeable cations in raw peats}

Amounts of metallic cations released by two types of peat when suspended in $2 \mathrm{M} \mathrm{HCl}$ solution are summarized in Table 1. Eutrophic peat contains much more calcium (1250 mequiv/kg d.w.) and iron (289 mequiv/kg d.w.) than oligotrophic peat (60 and 23.7 mequiv $/ \mathrm{kg} \mathrm{d}$.w., respectively). Both types of peat have a similar level of magnesium, sodium and potassium. There are few exchangeable heavy metals

Table 1. Proton exchangeable metal cations in eutrophic and oligotrophic raw peat: mean value of cation released by two samples of $3 \mathrm{~g}$ d.w. peat suspended in $100 \mathrm{ml} 2 \mathrm{M} \mathrm{HCl}$ solutions during $24 \mathrm{~h}$. All metal cation releases are referred to as peat dry weight in samples

\begin{tabular}{|c|c|c|c|c|c|c|c|c|c|c|c|c|}
\hline \multicolumn{13}{|c|}{ Eutrophic peat: } \\
\hline Element & $\mathrm{Na}$ & $\mathrm{K}$ & $\mathrm{Ca}$ & $\mathrm{Mg}$ & $\mathrm{Fe}$ & $\mathrm{Ni}$ & $\mathrm{Cu}$ & $\mathrm{Zn}$ & $\mathrm{Pb}$ & $\mathrm{Cr}$ & $\mathrm{Cd}$ & Total \\
\hline $\mathrm{mg} / \mathrm{kg}$ & 336.7 & 265.0 & 25000 & 1000 & 5400 & 33.3 & 16.7 & 13.3 & 6.7 & 31.7 & 0 & 32103 \\
\hline mequiv/kg & 14.6 & 6.8 & 1250 & 83.4 & 289.2 & 1.14 & 0.52 & 0.40 & 0.06 & 1.22 & 0 & 1650 \\
\hline \multicolumn{13}{|c|}{ Oligotrophic peat: } \\
\hline Element & $\mathrm{Na}$ & $\mathrm{K}$ & $\mathrm{Ca}$ & $\mathrm{Mg}$ & $\mathrm{Fe}$ & $\mathrm{Ni}$ & $\mathrm{Cu}$ & $\mathrm{Zn}$ & $\mathrm{Pb}$ & $\mathrm{Cr}$ & $\mathrm{Cd}$ & Total \\
\hline $\mathrm{mg} / \mathrm{kg}$ & 466.3 & 202.0 & 1200 & 870 & 440 & 30.0 & 16.7 & 13.3 & 41.7 & 23.3 & 0 & 3303 \\
\hline mequir $/ \mathrm{kg}$ & 20.3 & 5.2 & 60 & 72.6 & 23.7 & 1.14 & 0.52 & 0.40 & 0.40 & 0.90 & 0 & 185 \\
\hline
\end{tabular}


(0-1.2 mequiv/kg d.w.), in accordance to previous results by Glooschenko and Capoblanco (1982) using a mineralization method on a Canada peat.

This experiment shows that a total equivalent of 185 and 1650 mequiv $/ \mathrm{kg}$ d.w. cations occupy ion exchange sites in eutrophic and oligotrophic peat, respectively: these sites could probably participate in cation exchange when peat is in contact with a metal solution such as a cupric one, as noted by Kadlec and Keoleian (1986).

\section{Properties of copper fixation by peat}

The phenomenon of ion exchange between copper ions and calcium in eutrophic peat and magnesium or calcium in oligotrophic peat was observed by Gangiotti et al. (1986): he found that the number of equivalent released cations is always inferior to that of fixed copper, indicating that a reaction mechanism different to ion exchange may exist. An analysis of nitrate ion exchange accompanying copper fixation may be an effective way to study such adsorptioncomplexation mechanisms. Table 2 presents results of reaction between peat $(30 \mathrm{~g} \mathrm{d.w./1)}$ and cupric nitrate solution by monitoring $\mathrm{Cu}^{2+} \mathrm{Ca}^{2+}, \mathrm{Mg}^{2+} \mathrm{H}^{+}$ and $\mathrm{NO}_{3}^{-}$levels in initial and final equilibrium supernatant solutions.

Solution electroneutrality may be expressed by the $A$ ratio of anion and cation equivalent concentrations at equilibrium:

$$
A=\frac{\left(\mathrm{NO}_{3}^{-}\right)}{\left(\mathrm{H}^{+}\right)+2\left(\mathrm{Ca}^{2+}\right)+2\left(\mathrm{Mg}^{2+}+2\left(\mathrm{Cu}^{2+}\right)\right.}
$$

where ( ) refers to molar concentration. As this $A$ ratio only takes into account nitrate anion, any anion exchange will yield $A$ values lower than 1 . On the contrary $A$ values larger than 1 would indicate that cation exchange with species may not be taken into account in this charge balance. As shown on Table 2, $A$ values equal, under such concentration and $\mathrm{pH}$ conditions, 0.86 for eutrophic and 0.88 for oligotrophic peat, indicating that some limited anion exchange happened. Simultaneously a non-negligible amount of $\mathrm{NO}_{3}^{-}$was fixed on peat. It seems very likely that an equivalent amount of copper was fixed by peat in order to balance that negatively charged ions fixation: this property could be called molecular complexation of copper on peat. From the reaction of eutrophic peat with $10 \mathrm{mM}$ cupric solution (final $\mathrm{pH} 4.0), 0.403 \mathrm{mmol}$ of $\mathrm{NO}_{3}^{-}$were fixed: thus the amount of copper fixed with $\mathrm{NO}_{3}^{-}$was assumed to be 0.403 mequiv $/ \mathrm{kg}$. The total amount of fixed copper was equal to 1.933 mequiv, 1.53 mequiv copper was fixed by cation exchange. The amount of $\mathrm{Ca}^{2+}, \mathrm{Mg}^{2+}$ and $\mathrm{H}^{+}$released during that $\mathrm{Cu}^{2+}$ cation exchange was $(2 \times 7.55)+(2 \times 0.57)+0.09=16.3$ mequiv $/ 1$ or 1.63 mequiv in the $100 \mathrm{ml}$ solution. Both figures, i.e. 1.53 and 1.63 mequiv, being close to each other within experimental error of such determination, we think that the second part of copper fixed on peat, i.e. 1.53 mequiv, is indeed related to ion exchange. The reaction of copper ion with peat would thus be both ion exchange and adsorption-complexation. The amount of copper fixed by ion exchange reaches $84 \%$ under these experimental conditions. We will see below that this amount varies with free copper concentration or $\mathrm{pH}$ within the solution.

Similar results were found with $30 \mathrm{~g} \mathrm{d.w./1}$ oligotrophic peat at 2.5 final $\mathrm{pH}$ equilibrated with $10 \mathrm{mM}$ cupric nitrate solution: $55 \%$ of copper fixed was attributed to ion exchange and $45 \%$ to copper complexation.

As pointed out by Coupal and Lalancette (1976), peat is a rather complex material containing lignin and cellulose as major constituents. Peat carboxylic and phenolic groups are likely to be involved in chemical bonding. Cornell (1983) has shown that its microporosity varies with swelling: this porosity could explain high adsorption reactions yielding metal fixation capacities much larger than ion exchange capacities.

Influence of copper concentration upon its fixation by peat

Metal fixation isotherm ( $0-20 \mathrm{mM}$ cupric nitrate solution and $30 \mathrm{~g}$ d.w./1 of eutrophic peat with initial $\mathrm{pH}$ 5.0) shows us that there is no apparent saturation over that copper concentration range [Fig. 1(a)]. This result is in accordance with previous results obtained by Gosset et al. (1986), Gosset (1986), Gangiotti et al. (1986) and Gangneux et al. (1985) with the same material. The isotherm curve, however, could be split according to the type of reaction occurring: the

Table 2. Reaction in batch between $30 \mathrm{~g} \mathrm{d.w.} 1$ raw peat and $10 \mathrm{mM}$ cupric ions

\begin{tabular}{llllllll}
\hline & & $\mathrm{Cu}^{2+}$ & $\mathrm{Ca}^{2+}$ & $\mathrm{Mg}^{2+}$ & $\mathrm{H}^{+}$ & $\mathrm{NO}_{3}^{-}$ & $A$ \\
\hline Eutro. & $C_{\mathrm{i}}(\mathrm{mM})$ & 10.03 & 0.72 & 0 & $\begin{array}{c}0.01 \\
\mathrm{pH}=5.0 \\
0.10\end{array}$ & $20.06^{*}$ & 0.86 \\
& $C_{\mathrm{c}}(\mathrm{mM})$ & 0.38 & 8.27 & 0.57 & $\mathrm{pH}=4.0$ & 16.03 & \\
\hline & & & & & 0.32 & & \\
Oligo. & $C_{\mathrm{i}}(\mathrm{mM})$ & 9.69 & 0.87 & 0 & $\mathrm{pH}=3.5$ & $19.38^{*}$ & 0.88 \\
& $C_{\mathrm{c}}(\mathrm{mM})$ & 5.35 & 0.87 & 0.75 & $\begin{array}{c}3.39 \\
\mathrm{pH}=2.5\end{array}$ & 15.25 & \\
\hline
\end{tabular}

$C_{\mathrm{i}}=$ initial concentration

$C_{\mathrm{e}}=$ concentration at equilibrium.

*Value calculated from initial cupric nitrate concentration.

Eutro, = eutrophic peat.

Oligo = oligotrophic peat.

$A=$ ratio of electroneutrality, i.e. anion/cation equivalent concentration ratio. 

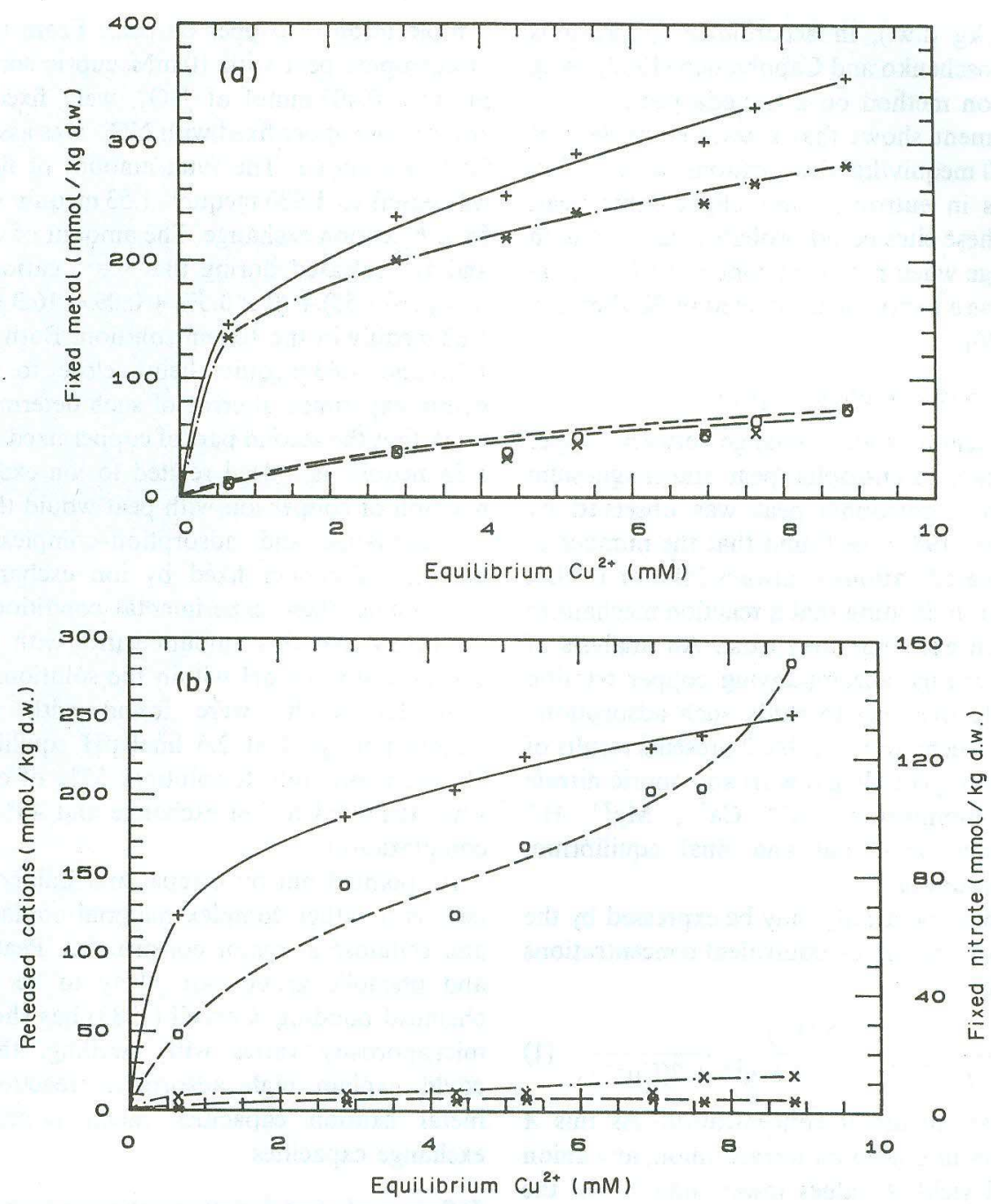

Fig. 1. (a) Influence of free copper content on amount of metal fixed on eutrophic peat. + , Total copper fixation; $*$, fraction of copper fixed by ion exchange; $O, x$, fraction of copper fixed by complexation using two approaches: $O$, calculated by subtracting ion-exchanged cupric ions from total amount of fixed copper; $x$, calculated from fixed nitrate ion amount. $1.5 \mathrm{~g} \mathrm{~d} . \mathrm{w}$. eutrophic peat equilibrated with $50 \mathrm{ml}$ of cupric solution in the $0-20 \mathrm{mM}$ initial range at initial pH 5.0 and final $\mathrm{pH}$ ranging from 3.6 to 5.0 . (b) Influence of free cupric concentration on cation release and nitrate fixation on eutrophic peat. + Calcium ion release; $x$, magnesium release; $*$, proton release; $O$, nitrate fixation. $1.5 \mathrm{~g}$ d.w. eutrophic peat equilibrated with $50 \mathrm{ml}$ of cupric solution in the $0-20 \mathrm{mM}$ initial range at initial $\mathrm{pH} 5.0$ and final pH ranging from 3.6 to 5.0 .

fixation due to ion exchange, determined by the number of equivalents of released cations $\left(\mathrm{H}^{+}, \mathrm{Ca}^{2+}\right.$, $\mathrm{Mg}^{2+}$ ), and the fixation due to complexation. The latter was determined using two methods: subtraction of ion exchange fraction from total fixed copper (in $\mathrm{mmol} / \mathrm{kg}$ d.w.) or use of nitrate fixation for evaluating copper complexation; as shown on Fig. 1(a) both methods gave very similar results. Obviously both approaches could not be used if the $A$ value of electroneutrality ratio had not been verified to be equal to 1 . In fact, the $A$ value, calculated from equation (1), ranged between 0.99 and 1.0 for all the points in Fig. 1(a). The ion exchange sites were relatively saturated and reached $280 \mathrm{mmol} / \mathrm{kg}$ d.w. whereas complexation ones reached only 0 and $21 \%$ in 0.5 and $9.0 \mathrm{mM}$ free cupric solutions. This suggests that the amount of ion exchange sites is limited. Thus, complexation would be responsible for the nonsaturation of isotherms. We will see later that, in $450 \mathrm{mM}$ free cupric solutions, complexation is responsible for $90 \%$ of total copper fixed on peat. The final $\mathrm{pH}$ of these samples ranges between 4.2 and 3.57 , with the lowest values corresponding to the highest initial cupric concentrations. But this amount of $\mathrm{H}^{+}$concentration variation is negligible $(10 \mathrm{mmol} / \mathrm{kg} \mathrm{d}$.w.) compared with that of fixed copper $(280 \mathrm{mmol} / \mathrm{kg}$ d.w. $)$ and released calcium ( $250 \mathrm{mmol} / \mathrm{kg} \mathrm{d.w.)} \mathrm{[Fig.} \mathrm{1(b)].} \mathrm{A} \mathrm{small} \mathrm{amount} \mathrm{of}$ magnesium release was also observed. On the contrary, ion exchange between copper ions and calcium plays an important role, indicating that ion exchange of raw eutrophic peat mainly occurs 
between $\mathrm{Cu}^{2+}$ and $\mathrm{Ca}^{2+}$. Nitrate fixation was observed to increase with cupric concentration: this was used to evaluate copper complexation shown in Fig. 1(a) curve $(x)$.

Similar behaviour was found with oligotrophic peat samples (0-20 $\mathrm{mM}$ initial cupric concentration and $30 \mathrm{~g}$ d.w./1 peat, initial $\mathrm{pH}$ 3.5): no apparent saturation of peat occurred in that copper concentration range and copper complexation seemed to be responsible for this non-saturation isotherm [Fig. 2(a)]. The electroneutrality $A$ values reached 0.95-1.1. Different from experiments with eutrophic peat, copper complexation became more important than ion exchange when free copper content was superior to $6 \mathrm{mM}$. An excellent accord was observed with both methods to evaluate complexation reactions. Here the final $\mathrm{pH}$ ranged between 2.5 and 3.5 and this $\mathrm{H}^{+}$release was important: indeed ion exchange takes place essentially between copper ions and $\mathrm{H}^{+}$[Fig. 2(b)]. Besides, magnesium and calcium ions are also partially responsible for this ion exchange mechanism. A plateau was found for $\mathrm{Ca}^{2+}$ and $\mathrm{Mg}^{2+}$ release, 25 and $20 \mathrm{mmol} / \mathrm{kg}$ d.w., respectively, over this cupric concentration range. A fixation of $\mathrm{NO}_{3}^{-}$was observed, showing that the amount of fixed $\mathrm{NO}_{3}^{-}$increased regularly with increasing initial cupric concentration.

Langmuir and Freundlich equations may be used to evaluate ion exchange and complexation isotherms. For a saturation-type curve of ion
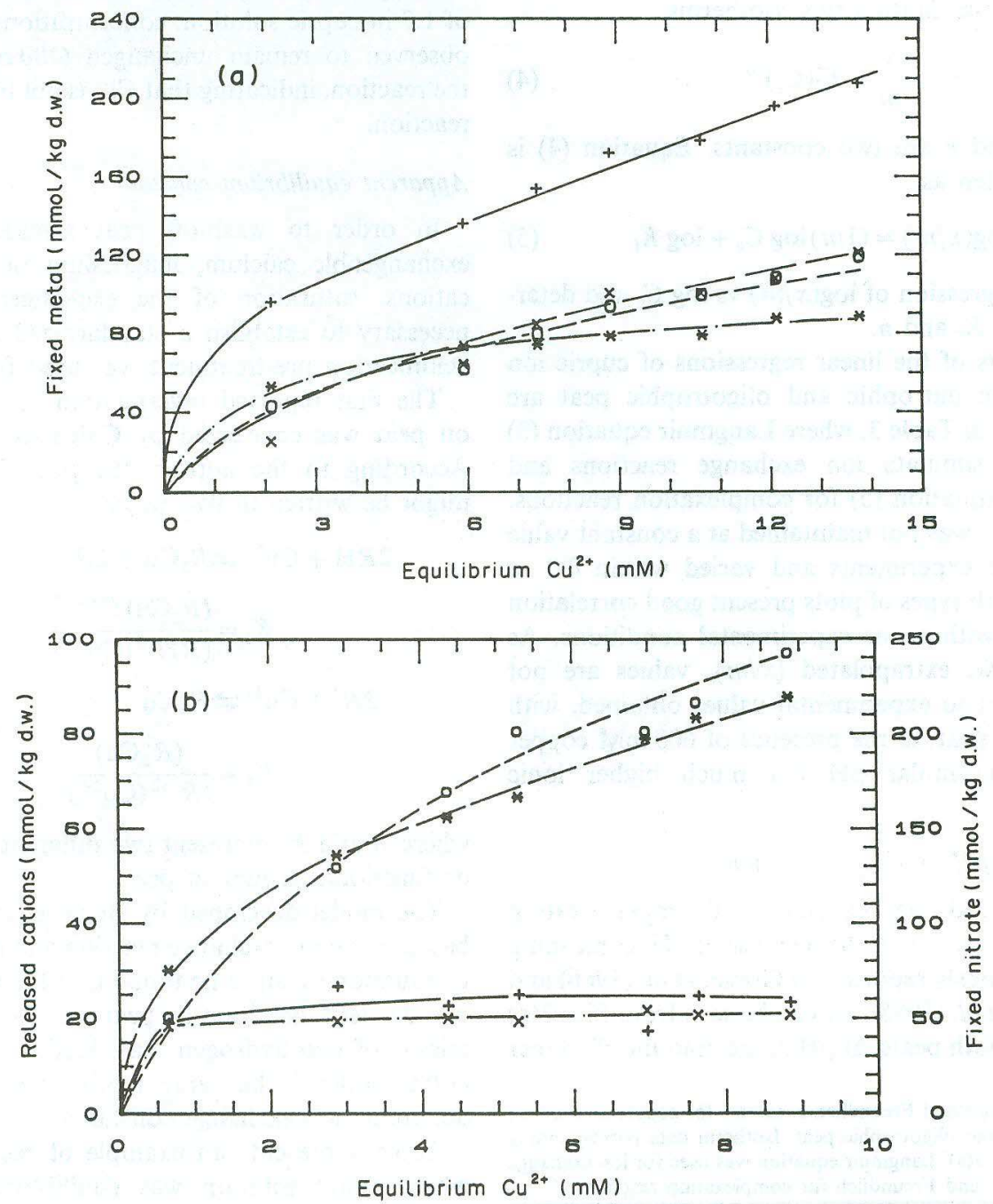

Fig. 2. (a) Influence of free copper content on amount of metal fixed oligotrophic peat. +, Total copper fixation; $*$, fraction of copper fixed by ion exchange; $O, x$, fraction of copper fixed by complexation using two approaches: $\bigcirc$, calculated by subtracting ion-exchanged cupric ions from total amount of fixed copper; $x$, calculated from fixed nitrate ion amount. $1.5 \mathrm{~g}$ d.w. oligotrophic peat equilibrated with $50 \mathrm{ml}$ of cupric solution in the $0-20 \mathrm{mM}$ initial range at initial pH 5.0 and final pH ranging from 2.5 to 5.0. (b) Influence of free cupric concentration on cations release and nitrate fixation on oligotrophic peat. + , Calcium ion release; $x$, magnesium release; $*$, proton release; $O$, nitrate fixation. $1.5 \mathrm{~g}$ d.w. oligotrophic peat equilibrated with $50 \mathrm{ml}$ of cupric solution in the $0-20 \mathrm{mM}$ initial range at initial pH 5.0 and final $\mathrm{pH}$ ranging from 2.5 to 3.5 
exchange fraction, the Langmuir equation might be used, which is expressed as:

$$
\frac{x}{m}=\frac{b(x / m)_{0} C_{\mathrm{e}}}{1+b C_{\mathrm{e}}}
$$

where $x / m$ represents fixed copper in $\mathrm{mmol} / \mathrm{kg}$ d.w., $C_{\mathrm{e}}$ being free cupric concentration in $\mathrm{mM}$ and $b$ referring to the Languir constant, $(x / m)_{0}$ being maximum capacity to fix copper. Equation (2) is usually transformed to (3):

$$
\frac{C_{\mathrm{e}}}{(x / m)}=\frac{1}{(x / m)_{0}} C_{\mathrm{e}}+\frac{1}{b(x / m)_{0}}
$$

for linear regression of $C_{\mathrm{e}} /(x / m)$ vs $C_{\mathrm{e}}$ and determination of $(x / m)_{0}$ and $b$.

The Freundlich equation is generally used to describe non-saturation-type isotherms:

$$
\frac{x}{m}=K_{\mathrm{f}}\left(C_{\mathrm{e}}\right)^{1 / n}
$$

where $K_{\mathrm{f}}$ and $n$ are two constants. Equation (4) is usually written as:

$$
\log (x / m)=(1 / n) \log C_{\mathrm{e}}+\log K_{\mathrm{f}}
$$

for linear regression of $\log (x / m)$ vs $\log C_{\mathrm{e}}$ and determination of $K_{\mathrm{f}}$ and $n$.

The results of the linear regressions of cupric ion isotherms on eutrophic and oligotrophic peat are summarized in Table 3, where Langmuir equation (3) is used to simulate ion exchange reactions and Freundlich equation (5) for complexation reactions. Although $\mathrm{pH}$ was not maintained at a constant value during these experiments and varied within 0.7 to 1.0 units, both types of plots present good correlation coefficients within our experimental conditions. As shown below, extrapolated $(x / m)_{0}$ values are not very different to experimental values obtained, with acid-treated peat, in the presence of $600 \mathrm{mM}$ copper solutions at similar $\mathrm{pH}$ but much higher ionic strength.

\section{Influence of $\mathrm{pH}$ on copper fixation}

We observed that capacities of copper fixation generally increase with the increase of $\mathrm{pH}$, confirming results previously reported by Gosset et al. (1986) and Gangneux et al. (1985). As can be seen from Figs 3(a) and (b) for both peats, at $\mathrm{pH} 2$, the amount of copper

Table 3. Langmuir and Freundlich constants for copper fixation on

\begin{tabular}{|c|c|c|c|c|c|c|}
\hline & \multicolumn{3}{|c|}{$\begin{array}{l}\text { Langmuir: } \\
\text { ion exchange }\end{array}$} & \multicolumn{3}{|c|}{$\begin{array}{l}\text { Freundlich: } \\
\text { complexation }\end{array}$} \\
\hline & $\begin{array}{c}(x / m)_{0} \\
(\mathrm{mmol} / \mathrm{kg})\end{array}$ & $\begin{array}{c}b \\
\left(\mathrm{mM}^{-1}\right)\end{array}$ & $r^{*}$ & $K_{\mathrm{f}}$ & $1 / n$ & $r^{*}$ \\
\hline Eutro. & 308 & 0.74 & 0.99 & 15.1 & 0.69 & 0.99 \\
\hline Oligo. & 101 & 0.44 & 0.99 & 25.1 & 0.56 & 0.98 \\
\hline
\end{tabular}
raw eutrophic and oligotrophic peat. Isotherm data corresponding to Figs 1(a) and 2(a). Langmuir equation was used for ion exchange reactions and Freundlich for complexation reactions fixation is much lower ( 147 and $57 \mathrm{mmol} / \mathrm{kg}$ d.w. for eutrophic and oligotrophic peat, respectively) than that at $\mathrm{pH}$ 3. At initial $\mathrm{pH}_{\mathrm{i}} 1.7$, both cupric ions and protons compete for ion exchange sites and an increase of $\mathrm{pH}$ was thus observed: equilibrium $\mathrm{pH}_{\mathrm{e}}$ reaching 2.54 and 2.10 in the supernatant for eutrophic and oligotrophic peat, respectively. Ion exchange and complexation fraction curves show that ion exchange is more $\mathrm{pH}$ dependent than complexation.

Electroneutrality $A$ values from equation (1) were found to be quite satisfactory, ranging between 0.94 and 1.1 over the $\mathrm{pH}$ range investigated, except for the 1.28 value obtained at $\mathrm{pH}_{\mathrm{e}} 2.1$ with oligotrophic peat. The concentration of $\mathrm{Cl}^{-}$was taken into account in determining $A$ values at the lowest $\mathrm{pH}$ values since $\mathrm{HCl}$ was added to reach a $\mathrm{pH}_{\mathrm{i}}$ of 1.7 in cupric solution: concentrations of $\mathrm{Cl}^{-}$were observed to remain unchanged $(700 \mathrm{mg} / \mathrm{l})$ through the reaction, indicating that $\mathrm{Cl}^{-}$is not involved in the reaction.

\section{Apparent equilibrium constant}

In order to wash-off peat samples from any exchangeable calcium, magnesium or other metal cations, saturation of the exchanger by $\mathrm{HCl}$ is necessary to establish a standardized system. Thus acidification pre-treatment was used for this study.

The first reported investigation of ion exchange on peat was conducted by Coleman et al. (1956). According to the author, the peat- $\mathrm{Cu}^{2+}$ reaction might be written in two ways:

$$
\begin{aligned}
2 R \mathrm{H}+\mathrm{Cu}^{2+} & \rightleftharpoons R_{2} \mathrm{Cu}+2 \mathrm{H}^{+} \\
K_{1} & =\frac{\left(R_{2} \mathrm{Cu}\right)\left(\mathrm{H}^{+}\right)^{2}}{(R \mathrm{H})^{2}\left(\mathrm{Cu}^{2+}\right)} \\
2 R^{\prime}+\mathrm{Cu}^{2+} & \rightleftharpoons R_{2}^{\prime} \mathrm{Cu} \\
K_{\mathrm{f}}^{\prime} & =\frac{\left(R_{2}^{\prime} \mathrm{Cu}\right)}{\left(R^{\prime}\right)^{2}\left(\mathrm{Cu}^{2+}\right)}
\end{aligned}
$$

where $R$ and $R^{\prime}$ represent two different reactive sites or functional groups of peat.

The model developed by Bunzl et al. (1976) was based on an ion exchange reaction and is thus similar to equation (6) since he found that the adsorption of one divalent metal ion by peat was coupled with the release of two hydrogen ions. Kadlec and Keoleian (1986) utilized the same mechanism as Bunzl to determine ion exchange constants.

Table 4 presents an example of results obtained when cupric solution was equilibrated with preacidified peat. It demonstrates that with both peat types, the processes are the same as with raw peat: $A$ values reach 1.03 with the eutrophic peat and 1.01 with the oligotrophic one, indicating an absence of anion exchange. An ion exchange reaction occurs between $\mathrm{Cu}^{2+}$ and $\mathrm{H}^{+}$, but some nitrate ion depletion shows that complexation is also occurring with preacidified ion exchange peat samples. 

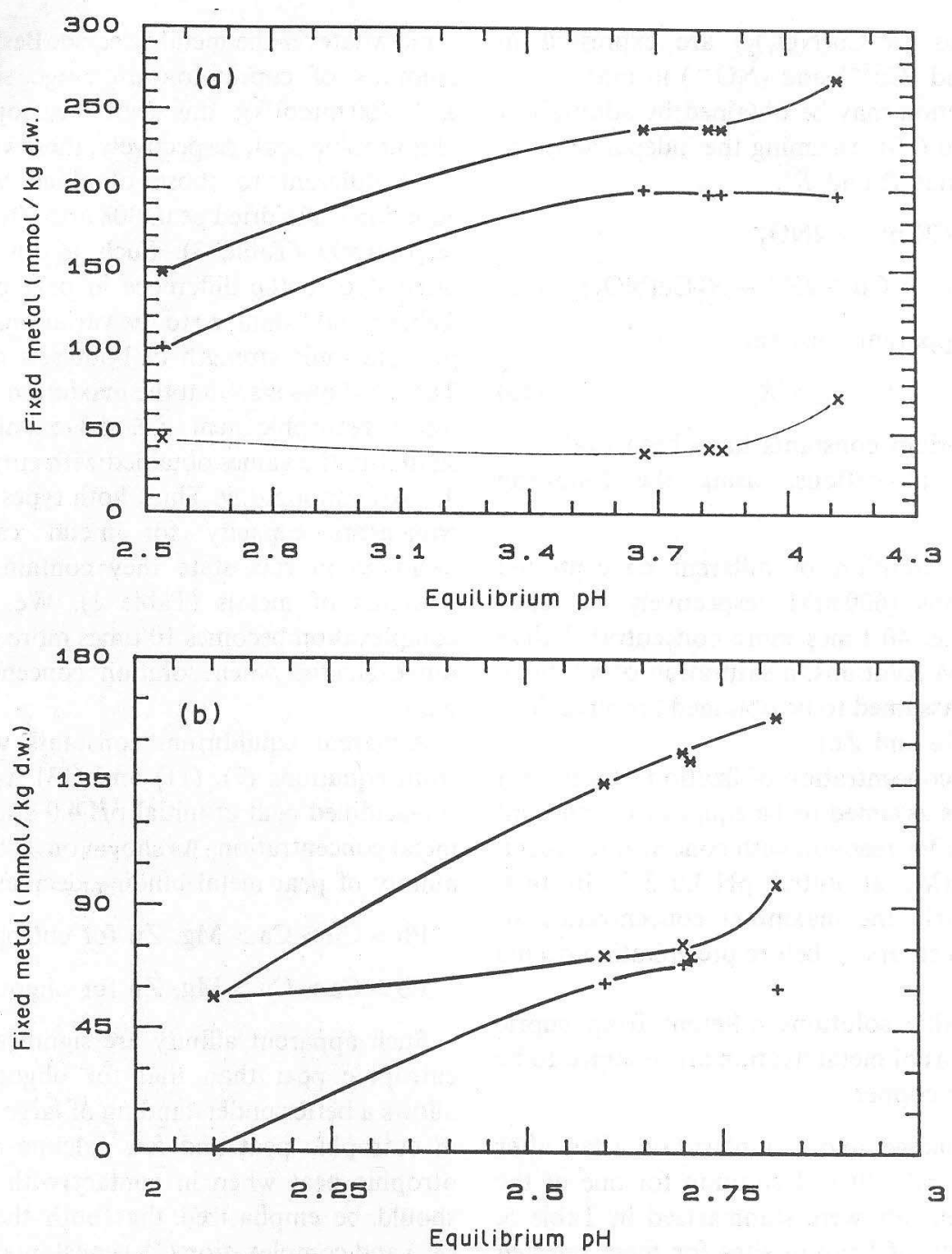

Fig. 3. (a) Influence of $\mathrm{pH}$ on copper fixation. *, Total fixed copper; + , copper fixed by ion exchange; $x$, copper fixed by complexation. $1.5 \mathrm{~g} \mathrm{~d}$.w. eutrophic peat equilibrated with $50 \mathrm{ml} 10 \mathrm{mM}$ cupric solution for initial $\mathrm{pH}$ ranging from 1.7 to 6.0 . (b) Influence of $\mathrm{pH}$ on copper fixation. *, Total fixed copper; + , copper fixed by ion exchange; $x$, copper fixed by complexation. $1.5 \mathrm{~g}$ d.w. oligotrophic peat equilibrated with $50 \mathrm{ml} 10 \mathrm{mM}$ cupric solution for initial $\mathrm{pH}$ ranging from 1.7 to 6.0 .

Reactions have been expressed by equation with apparent constant: (6). Reaction (8) was modified for complexation reactions, considering $\mathrm{NO}_{3}^{-}$fixation:

$$
2 R^{\prime}+\mathrm{Cu}^{2+}+2 \mathrm{NO}_{3}^{-} \rightleftharpoons R_{2}^{\prime} \mathrm{Cu}\left(\mathrm{NO}_{3}\right)_{2}
$$

$$
K_{2}=\frac{\left(R_{2}^{\prime} \mathrm{Cu}\left(\mathrm{NO}_{3}\right)_{2}\right)}{\left(R^{\prime}\right)^{2}\left(\mathrm{Cu}^{2+}\right)\left(\mathrm{NO}_{3}^{-}\right)^{2}}
$$

\begin{tabular}{|c|c|c|c|c|c|c|c|}
\hline & te & $\mathrm{Cu}^{2+}$ & $\mathrm{Ca}^{2+}$ & $\mathrm{Mg}^{2+}$ & $\mathrm{H}^{+}$ & $\mathrm{NO}_{3}^{-}$ & $A$ \\
\hline \multirow[t]{2}{*}{ Eutro. } & $C_{\mathrm{i}}(\mathrm{mM})$ & 14.74 & 0.27 & - & $\begin{array}{c}0.10 \\
\mathrm{pH}=4.0 \\
9.33\end{array}$ & $29.48^{*}$ & \multirow[t]{2}{*}{1.03} \\
\hline & $C_{\mathrm{c}}(\mathrm{mM})$ & 6.59 & 0.26 & - & $\mathrm{pH}=2.03$ & 23.66 & \\
\hline \multirow[t]{2}{*}{ Oligo. } & $C_{\mathrm{i}}(\mathrm{mM})$ & 14.52 & - & 0 & $\begin{array}{c}0.10 \\
\mathrm{pH}=4.0 \\
5.56\end{array}$ & $29.04^{*}$ & \multirow[t]{2}{*}{1.01} \\
\hline & $C_{\mathrm{c}}(\mathrm{mM})$ & 8.93 & - & 0.01 & $\mathrm{pH}=2.25$ & 23.73 & \\
\hline
\end{tabular}

Table 4. Reaction in batch between $30 \mathrm{~g}$ d.w./1 pre-acidified peat and $10 \mathrm{mM}$ copper ions

$C_{\mathrm{i}}=$ initial concentration.

$C_{\mathrm{c}}=$ concentration at equilibrium.

*Value calculated from initial cupric nitrate concentration.

Eutro. = eutrophic peat.

Oligo. = oligotrophic peat.

$A=$ electroneutrality ratio. 
where $\left(R^{\prime}\right)$ and $\left(R_{2}^{\prime} \mathrm{Cu}\left(\mathrm{NO}_{3}\right)_{2}\right)$ are expressed in $\mathrm{mmol} / \mathrm{g}$ d.w. and $\left(\mathrm{Cu}^{2+}\right)$ and $\left(\mathrm{NO}_{3}^{-}\right)$in $\mathrm{mM}$.

A global reaction may be obtained by addition of reactions (6) and (10), assuming the independence of both reaction sites $R$ and $R^{\prime}$ :

$$
\begin{aligned}
2 R \mathrm{H}+2 \mathrm{R}^{\prime}+ & 2 \mathrm{Cu}^{2+}+2 \mathrm{NO}_{3}^{-} \\
& \rightleftharpoons R_{2} \mathrm{Cu}+2 \mathrm{H}^{+}+R_{2}^{\prime} \mathrm{Cu}\left(\mathrm{NO}_{3}\right)_{2}
\end{aligned}
$$

with a global apparent constant

$$
K=K_{1} \times K_{2} .
$$

These equilibrium constants have been evaluated for several metal cations, using the following assumptions:

(1) With an addition of different concentrated metallic solutions $(600 \mathrm{mM}$ respectively for each metal cation), i.e. 40 times more concentrated than the usual $15 \mathrm{mM}$ solutions, a saturation of all metal fixation sites is assumed to be obtained for all cations $(\mathrm{Pb}, \mathrm{Cu}, \mathrm{Ca}, \mathrm{Mg}$ and $\mathrm{Zn})$.

(2) The total concentration of fixation sites in peat $(R \mathrm{H})$ and $\left.R^{\prime}\right)$ is assumed to be equal to the amount of cation fixed after reaction with concentrated metal solution $(600 \mathrm{mM})$ at initial $\mathrm{pH} 3.0-3.3$. In fact, $600 \mathrm{mM}$ in nearly the maximum concentration of copper and lead solutions before precipitation occurs at that $\mathrm{pH}$.

(3) For metallic solutions different from cupric ones, mechanisms of metal fixation are assumed to be the same as for copper.

The ion exchange and complexation sites after addition of 15 and $600 \mathrm{mM}$ solution for one of the five selected elements were summarized in Table 5. The homogeneity of fixation sites for these selected metals could be seen from total $(x / m)_{0}$ values, varying between 4.3 and $5.3 \mathrm{mmol} / \mathrm{g}$ d.w. except for the $\mathrm{Zn}$ fixation sites on oligotrophic peat $(6.8 \mathrm{mmol} / \mathrm{g}$ d.w.), implying that the fixation sites are probably the same whatever the metal selected. Besides, maximum amounts of cupric ion exchange sites reach 380 and $260 \mathrm{mmol} / \mathrm{kg}$ d.w. with eutrophic peat and oligotrophic peat, respectively; these values are somewhat different to those obtained with Langmuir equation using dried peat: 308 and $101 \mathrm{mmol} / \mathrm{kg}$ d.w., respectively (Table 3). Such a difference may be attributed to the difference in peat pretreatment of Table 3 and 5 data, or to the variations in equilibrium $\mathrm{pH}$ and ionic strength of both sets of experiments. Table 5 shows also that the maximum amount of sites for oligotrophic peat, i.e. $4.3-5.3 \mathrm{mmol} / \mathrm{g}$ d.w., is similar to the values obtained with eutrophic peat, i.e. $4.5-6.8 \mathrm{mmol} / \mathrm{g} \mathrm{d}$.w. Thus, both types of peat exhibit equivalent capacity for metal cation fixation, although in raw state they contain very different amounts of metals (Table 1). We observed that, complexation becomes 10 times more important than ion exchange when solution concentration is very high.

Apparent equilibrium constants were calculated from equations (7), (11) and (13) using $30 \mathrm{~g}$ d.w./1 pre-acidified peat at initial $\mathrm{pH} 4.0$ and $15 \mathrm{mM}$ initial metal concentration. As shown on Table 6, the global affinity of peat metal binding decreases as:

$$
\begin{aligned}
& \mathrm{Pb}>\mathrm{Cu}>\mathrm{Ca}>\mathrm{Mg}, \mathrm{Zn} \text { for eutrophic peat, } \\
& \mathrm{Pb}>\mathrm{Ca}>\mathrm{Cu}>\mathrm{Mg}, \mathrm{Zn} \text { for oligotrophic peat. }
\end{aligned}
$$

Such apparent affinity are significantly larger for eutrophic peat than that for oligotrophic one. It allows a better understanding of large calcium release in eutrophic peat and few calcium release in oligotrophic peat when in contact with cupric ions. It should be emphasized that both the ion exchange $\left(K_{1}\right)$ and complexation $\left(K_{2}\right)$ constants are conditional stability constants since their value may be dependent upon experimental conditions such as $\mathrm{pH}$, ionic

\begin{tabular}{|c|c|c|c|c|c|c|c|c|c|}
\hline \multicolumn{10}{|c|}{ Eutrophic peat: } \\
\hline \multirow[b]{2}{*}{$C_{\mathrm{i}}$} & \multicolumn{4}{|c|}{$15 \mathrm{mM}$} & \multicolumn{5}{|c|}{$600 \mathrm{mM}$} \\
\hline & $\mathrm{pH}_{\mathrm{i}}$ & $\mathrm{pH}_{\mathrm{e}}$ & $(x / m)_{1}$ & $(x / m)_{2}$ & $\mathrm{pH}_{\mathrm{i}}$ & $\mathrm{pH}_{\mathrm{e}}$ & $(x / m)_{1}$ & $(x / m)_{2}$ & $(x / m)_{0}$ \\
\hline $\mathrm{Pb}$ & 4 & 1.93 & 0.20 & 0.11 & 3.2 & 1.68 & 0.55 & 4.09 & 4.6 \\
\hline $\mathrm{Cu}$ & 4 & 2.03 & 0.16 & 0.12 & 3.0 & 1.88 & 0.38 & 4.97 & 5.3 \\
\hline $\mathrm{Ca}$ & 4 & 2.35 & 0.07 & 0.12 & 3.4 & 2.32 & 0.15 & 4.13 & 4.3 \\
\hline $\mathrm{Mg}$ & 4 & 2.37 & 0.07 & 0.11 & 3.3 & 2.22 & 0.17 & 4.33 & 4.5 \\
\hline $\mathrm{Zn}$ & 4 & 2.25 & 0.10 & 0.07 & 3.8 & 2.07 & 0.24 & 4.20 & 4.4 \\
\hline \multicolumn{10}{|c|}{ Oligotrophic peat: } \\
\hline & \multicolumn{4}{|c|}{$15 \mathrm{mM}$} & \multicolumn{5}{|c|}{$600 \mathrm{mM}$} \\
\hline$C_{\mathrm{i}}$ & $\mathrm{pH}_{\mathrm{i}}$ & $\mathrm{pH}_{\mathrm{e}}$ & $(x / m)_{1}$ & $(x / m)_{2}$ & $\mathrm{pH}_{\mathrm{i}}$ & $\mathrm{pH}_{\mathrm{e}}$ & $(x / m)_{1}$ & $(x / m)_{2}$ & $(x / m)_{0}$ \\
\hline $\mathrm{Pb}$ & 4 & 2.30 & 0.08 & 0.13 & 3.2 & 2.05 & 0.23 & 4.23 & 4.4 \\
\hline $\mathrm{Cu}$ & 4 & 2.25 & 0.09 & 0.09 & 3.0 & 2.00 & 0.26 & 4.42 & 4.7 \\
\hline $\mathrm{Ca}$ & 4 & 2.52 & 0.05 & 0.17 & 3.2 & 2.19 & 0.15 & 4.41 & 4.6 \\
\hline $\mathrm{Mg}$ & 4 & 2.52 & 0.05 & 0.12 & 3.2 & 2.30 & 0.15 & 4.97 & 5.1 \\
\hline $\mathrm{Zn}$ & 4 & 2.43 & 0.06 & 0.10 & 3.4 & 2.39 & 0.13 & 6.73 & 6.8 \\
\hline
\end{tabular}
strength which varied between 60 and $30 \mathrm{mM}$ before and after equilibrium in this set of experiments, peat

Table 5. Initial and equilibrium conditions for the determination of apparent constants, using $30 \mathrm{~g} \mathrm{d.w./1}$ pre-acidified peat

$(x / m)_{1}=$ ion exchange capacities in $\mathrm{mmol} / \mathrm{g} \mathrm{d} . \mathrm{w}$.

$(x / m)_{2}=$ complexation capacities in $\mathrm{mmol} / \mathrm{g} \mathrm{d} . \mathrm{w}$.

$(x / m)_{0}=$ total fixation capacities in $\mathrm{mmol} / \mathrm{g}$ d.w., i.e. both ion exchange and complexation sites determined by addition of $100 \mathrm{ml} 15 \mathrm{mM}$ and then $600 \mathrm{mM}$ solutions. 
